\title{
Um software para a análise do desenvolvimento do pensamento geométrico segundo o modelo de Van Hiele
}

\author{
Software for the analysis of the development of geometric thinking according \\ to Van Hiele model
}

Matheus dos Santos Souza

Marcelo de Oliveira Dias

\begin{abstract}
Resumo: 0 artigo apresenta resultados de uma monografia de licenciatura em Matemática em que buscou-se identificar níveis do pensamento geométrico dos estudantes da disciplina Fundamentos da Geometria, no Instituto do Noroeste Fluminense de Educação Superior. Os estudos partiram das prescrições curriculares previstas até o Ensino Médio e por meio da aplicação da teoria de Van Hiele, utilizando o software estruturado GeoRun para a identificação dos níveis dos pensamentos. A metodologia adotada foi a Engenharia Didática, para a qual foi realizada uma análise preliminar que traçou um perfil inicial da amostra, a análise a priori, experimentação, donde foi realizada uma sessão de ensino com um software de Geometria dinâmica e, por fim, a validação/análise a posteriori da qual foi realizada uma comparação dos resultados obtidos e a validação do estudo. Foi concluído que a intervenção pedagógica
\end{abstract} potencializou a compreensão da turma e houve uma evolução nesse reestudo dos conceitos das figuras geométricas.

Palavras-chave: Teoria de Van Hiele. Engenharia Didática. Ambiente computacional. Geometria.

Abstract: The article presents results of a monograph in Mathematics that sought to identify levels of geometric thinking of the students of the Fundamentals of Geometry discipline at the Northwest Fluminense Institute of Higher Education. The studies started from the curricular prescriptions until high school and by applying Van Hiele theory using the GeoRun structured software for the identification of the thought levels. The methodology adopted was the Didactic Engineering, where a preliminary analysis was carried out which traced an initial profile of the sample, the a priori analysis, experimentation, where a teaching session with a dynamic geometry software was held and finally the validation / analysis to after which a comparison of the results obtained

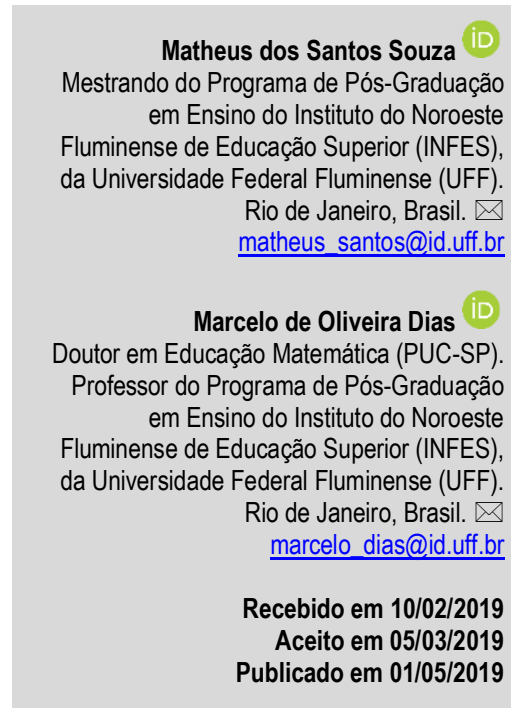
and the study validation was performed. It was concluded that the pedagogical intervention enhanced the understanding of the class and there was an evolution in this restudy of the concepts of geometric figures.

Keywords: Van Hiele theory. Didactic Engineering. Computational environment. Geometry.

\section{Introdução}

O presente trabalho retrata parte de uma pesquisa realizada para a obtenção do grau de Licenciado em Matemática na Universidade Federal Fluminense. Com a indagação de uma 
metodologia que suprisse a demanda deste trabalho, a Engenharia Didática foi adotada para norteá-lo. Por sua vez, ela é composta por quatro fases: análise preliminar, análise a priori, experimentação e validação/ análise a posteriori. Na análise preliminar, foi realizado um levantamento anão documento preliminar Base Nacional Comum Curricular - BNCC (BRASIL, 2016), referente ao Ensino Fundamental e Ensino Médio, buscando os conteúdos de Geometria que devem ser estudados, segundo esse documento.

$\mathrm{Na}$ análise a priori, de acordo com o levantamento de dados da Cetic.br ${ }^{1}$, a tecnologia está inserida na sociedade por meio de smartphones, tablets, computadores entre outros recursos tecnológicos. Especialistas e pesquisadores da área como Alves (2007), Miranda (2007) e Alves e Sampaio (2010), entre outros, consideram que a tecnologia deve ser inserida no contexto escolar. A BNCC (BRASIL, 2016) não oferece aportes teóricos para os professores, mas indica 0 uso nas aulas de Matemática. Nesse viés foi desenvolvido um jogo denominado GeoRun na plataforma Scratch 1.4, levando em consideração o modelo teórico de Van Hiele.

O modelo de Van Hiele é composto por cinco níveis. No nível 1 (visualização), que exige reconhecimento da figura geométrica por meio de considerações visuais; no nível 2, o aluno é capaz de reconhecer as figuras geométricas a partir de suas propriedades, todavia, sem realizar articulação entre elas. Desse modo, não faz inclusão de classe. No nível 3, esse aluno já é capaz de estabelecer relações de inferência entre essas propriedades, então, é capaz de fazer inclusão de classe. Contudo, não consegue fazer uma demonstração, uma prova - isso só ocorre no nível seguinte, nível 4; no nível 5, o aluno trabalha com diferentes geometrias.

Entretanto, na pesquisa, o jogo propõe apenas os três primeiros níveis do modelo teórico, pois os conteúdos que estão relacionados a esses níveis são aqueles que os estudantes já deveriam ter conhecimento ao término do Ensino Médio. Com a aplicação do jogo na análise a priori é possivel identificar os pensamentos geométricos que os alunos já possuem, para que sejam estruturadas atividades de acordo com seus níveis. As atividades servem como auxílio para a superação de suas dificuldades, promovendo a evolução pelos níveis do modelo, possibilitando o desenvolvimento da capacidade para desempenhar estratégias com um rol de conhecimentos amplos frente a situações-problema, desenvolvendo-as de forma consciente e clara.

\footnotetext{
${ }^{1}$ A Cetic.br foi criada em 2005 com a missão de monitorar a adoção das tecnologias de informação e comunicação
} (TIC) - em particular, o acesso e uso de computador, internet e dispositivos móveis. 
$\mathrm{Na}$ experimentação, foi levado em consideração o levantamento de todos os dados e aplicações realizadas. Este foi o momento em que foram aplicadas as atividades estruturadas de acordo com o resultado obtido na aplicação do GeoRun. A utilização de um software de geometria dinâmica (GeoGebra) foi adotada para relembrar ou para proporcionar a construção do conhecimento da amostragem. Já na validação e análise a posteriori, encontra-se no momento final, donde juntou-se todos os dados e foi realizada a confrontação entre eles, podendo validar a Engenharia Didática.

Para a pesquisa, foi realizada uma revisão bibliográfica sobre o tema estudado, o que trouxe contribuições teóricas. Evidenciou-se também uma escassez de trabalhos envolvendo a Engenharia Didática com o modelo de Van Hiele. De modo geral, o objetivo foi desenvolver o GeoRun para identificar o pensamento geométrico e planejar um posterior estudo da Geometria Plana com auxílio do software GeoGebra, potencializando a visualização dos estudantes.

O modelo junto à metodologia visou à compreensão dos conteúdos aos quais Ihes foram avaliados. Desse modo, a sessão de ensino foi organizada de acordo com o conhecimento dos estudantes, com o intuito de proporcionar melhor aprendizagem dos conteúdos de Geometria. A pesquisa permitiu avaliar o rendimento dos estudantes inscritos na disciplina de Fundamentos da Geometria², obrigatória no segundo semestre do programa curricular do curso de Matemática modalidades licenciatura e bacharelado — oferecido pela Universidade Federal Fluminense.

\section{Revisão bibliográfica}

Para o início da construção deste trabalho foi realizado um levantamento de trabalhos análogos, que também abordam a teoria de Van Hiele e o ensino da Geometria por meio de softwares. As abordagens trazem contribuições relevantes para a presente investigação. Os contextos tratam da teoria de Van Hiele e aspectos relacionados à Tecnologia na educação, relatando contribuições e limitações da sua utilização no campo de Educação Matemática.

A monografia desenvolvida por Barros (2009) evidenciou a estrutura do modelo teórico de Van Hiele com a adaptação ao ambiente computacional. Seu objetivo foi analisar o nível do pensamento geométrico dos estudantes de acordo com as indicações dos Parâmetros Curriculares Nacionais de Matemática - PCN (BRASIL, 2002). Com o jogo desenvolvido foi

\footnotetext{
2 Disciplina obrigatória oferecida no segundo semestre de Matemática (licenciatura e bacharelado) no Instituto do Noroeste Fluminense de Educação Superior (INFES) na Universidade Federal Fluminense.
} 
possível evidenciar o nível de pensamento geométrico por meio dos erros e acertos. A análise foi realizada com os estudantes do primeiro ano do Ensino Médio. Das seleções, este trabalho foi 0 que trouxe maior contribuição, mas limita-se apenas a indicar o nível em que o estudante está de acordo com o modelo. Com esses indícios, o autor pode direcionar, posteriormente, estudos para que os alunos consigam compreender os conceitos geométricos a partir dos níveis em que se encontram.

Em seu artigo, Alves e Sampaio (2010) trazem o modelo de Van Hiele e resultados obtidos durante testes elaborados pela equipe do Projeto Fundão abrangendo o reconhecimento de quadriláteros e suas propriedades. Ainda, após aplicações apresentam as contribuições que 0 software pode proporcionar no ensino da Geometria. Esses autores evidenciam que o computador pode desenvolver novos ambientes e novas formas de pensar e agir, contribuindo para a aquisição de novos conhecimentos.

Outro caso é de Morelatti e Souza (2006), que identificaram o conhecimento dos estudantes que seriam professores dos anos iniciais do Ensino Fundamental, adotando como metodologia o modelo teórico de Van Hiele. Foi avaliado o conhecimento por meio de uma prova diagnóstica; a mesma continha apenas conteúdos exigidos para o Ensino Fundamental, expressos nos Parâmetros Curriculares Nacionais de Matemática (BRASIL, 1998). A partir deste diagnóstico, os autores elaboraram um estudo com software de geometria dinâmica, obtendo melhor resultado, chegando à conclusão que o computador potencializou o ensino.

Os autores trazem a tecnologia e conseguem utilizar desta para abordar os conteúdos geométricos, possibilitando a observação, e por meio do software conseguem enriquecer a construção do conhecimento. Assim, no caso da Geometria, é possível que as alterações das figuras planas possam proporcionar diferentes situações de visualizações, podendo alterar as propriedades e nomes de acordo com a variação de qualquer vértice. Por exemplo, se alterarmos um vértice do retângulo, este pode se tornar um quadrilátero. Desse modo, com o auxílio do software essas situações surgem naturalmente.

Alves (2007) utilizou-se de uma sequência didática de Cavalieri e um software de Geometria dinâmica para verificar a contribuição da ferramenta no ensino. A investigação foi realizada em uma escola técnica onde havia duas amostragens, uma com aulas em laboratórios de informática e a outra com aulas tradicionais. A análise foi realizada por meio de avaliações. $A$ visualização mostrou-se de grande importância para a aprendizagem geométrica. Com o estudo, 
verificou-se a potencialização do uso de software para o ensino da Geometria nas aplicações, pois os resultados da turma do laboratório de informática foram melhores do que a turma tradicional.

O artigo elaborado por Miranda (2007) é relevante ao mostrar a realidade do ensino, trazendo abordagens sobre as Tecnologias da Informação e Comunicação. As atividades ajustadas para a realização da pesquisa visavam à maximização dos processos de ensino e de aprendizagem. A investigação ocorrida constata que o uso deste recurso por docentes sem conhecimentos prévios, ocasiona o fracasso na prática pedagógica. A autora destaca não ser apenas o computador, mas um conjunto de variáveis que podem potencializar o ensino e a aprendizagem. Nesse sentido, é preciso que os professores deem suportes aos estudantes, quando há a alteração do tradicional para o inovador.

No presente trabalho tem-se por objetivo identificar o nível de pensamento geométrico dos estudantes e posteriormente auxiliá-los a progressão destes níveis, baseando no modelo de Van Hiele. A revisão bibliográfica realizada reforça a eficácia do uso de tecnologias na aprendizagem. Assim, para a abordagem dos conteúdos como figuras geométricas e suas propriedades, adotouse um software visando à compreensão dos estudantes, tanto teórica como visual.

Os trabalhos apresentados também contribuíram para a reflexão dos recursos didáticos e os auxílios tecnológicos para os processos de ensino e de aprendizagem. Ainda, há poucos trabalhos envolvendo a Engenharia Didática com o modelo de Van Hiele.

\section{Embasamento teórico}

A Geometria é um conteúdo que relacionado intrinsicamente à visualização; pode-se perceber em praticamente tudo em que é possível ver. O tema de Geometria relaciona-se também com o de Grandezas e Medidas, como altura, áreas, distância, entre outros.

O modelo de Van Hiele foi adotado para essa pesquisa. Os níveis de desenvolvimento do pensamento descritos do modelo teórico foram baseados em Kaleff et al. (1994), os quais passaremos a apresentar.

No Nível 1 (Visualização ou Reconhecimento), os alunos conseguem assimilar as figuras por meio de considerações visuais, de conceitos geométricos obtidos de forma geral, sem conseguir fazer considerações claras sobre as propriedades. Aprendem de forma mecânica 0 
vocabulário geométrico, conseguem identificar formas específicas e tentam repetir o conceito visual com outra figura dada.

No Nível 2 (Análise), os alunos conseguem fazer uma análise informal, mas não conseguem fazer definições abstratas, apenas relacionam conceitos e características de figuras geométricas e estabelecem conceitos de classes e formas.

Quanto ao Nível 3 (Dedução Informal), os alunos percebem a necessidade de uma definição abstrata, que uma propriedade pode depender da outra, estabelecendo relações entre as figuras, conseguindo fazer uma definição precisa, sendo também capazes de acompanhar provas reais.

Em relação ao Nível 4 (Dedução Formal), esse exige capacidade para compreender a dedução e o papel dos axiomas, postulados, teoremas e provas, conseguem demonstrar resultados de diferentes maneiras, por meio das definições e teoremas.

Já no Nível 5 (Rigor), os alunos precisam de desenvolver habilidades para analisar sistemas dedutivos com um alto grau de rigor e conseguem trabalhar em cima de sistemas baseados em axiomas, sendo capazes de estudar geometrias não euclidianas.

Entretanto, o jogo GeoRun foi adaptado até o nível 3, pois foi considerado os conteúdos prescritos pela BNCC (BRASIL, 2016). Para gerir a intervenção com o jogo, foi adotado também o contrato didático, definido como

\footnotetext{
o conjunto de comportamentos do professor que são esperados pelos estudantes e 0 conjunto de comportamentos do aluno que são esperados pelo professor [...] Esse contrato é o conjunto de regras que determinam uma pequena parte explicitamente, mas sobretudo implicitamente, do que cada parceiro da relação didática deverá gerir e daquilo que, de uma maneira ou de outra, ele terá de prestar conta perante 0 outro (BROUSSEAU, 1986 apud SILVA, 2016, p. 50).
}

As principais propriedades/características do modelo de Van Hiele estão descritas de acordo com Kaleff et al. (1994) e Nasser (2015).

(1) O modelo é parte de uma teoria de desenvolvimento do pensamento, logo, ele ocorre de uma forma sequencial por meio de aprendizagens. Para que o estudante consiga se sair bem no nível presente, deve possuir conhecimentos específico anteriores, portanto não é possível pular os níveis e sim apenas passá-los de forma que tenha o conhecimento necessário de cada. 
(2) O avanço ocorrido ou o nível presente do estudante não depende de sua idade, mas do que foi estudado e qual tipo de ensino foi empregado sobre ele, um mais novo pode ter conhecimentos e estar em um nível superior ao que possui idade mais avançada.

(3) O esquema realizado, é um mecanismo dinâmico da estrutura de níveis, os estudos ocorrem em sequência assim como a teoria, ao começar se tem apenas a visualização das figuras geométricas, ao avançar de nível, se tornam um estudo mais aprimorado do que o nível anterior, funcionando hierarquicamente.

(4) Os símbolos linguísticos, podem variar de acordo com cada nível, uma relação que era aceita em um nível anterior, pode não ser aceita em um nível posterior, por cada nível que se passa a linguagem fica mais formal e rigorosa, apura-se assim o vocabulário e conhecimento.

(5) Para que uma atividade seja feita e compreendida, o estudante deve ter conhecimentos prévios necessários para realizar a atividade, caso contrário, a realização da mesma não conseguirá proporcionar uma boa aprendizagem a ele.

\section{Metodologia}

A Engenharia Didática tem como primeira fase, a análise preliminar, em se se visa analisar os conhecimentos prévios da amostra. Machado (2016) sugere alguns pontos a serem analisados:

- O conhecimento e os problemas relacionados aos conteúdos propostos pelo ensino;

- O ensino dos dias de hoje e os efeitos sofridos por ele;

- A produção dos estudantes, tomando em consideração as dificuldades e os obstáculos que impedem sua evolução;

- A área com dificuldade na qual irá focar a concretização didática.

Nessa primeira etapa, são identificados os conteúdos que os estudantes deveriam compreender, por meio dos documentos curriculares. Assim é realizada uma análise prévia dos conhecimentos.

A segunda fase, análise a priori, tem-se traçado o perfil inicial da amostra obtido na etapa anterior. Logo, deve definir as variáveis a serem utilizadas, podendo ser macrodidáticas, referentes à organização global da engenharia, ou microdidáticas, referentes à organização local da engenharia, onde a organização é realizada em uma sessão ou em uma fase. Essas variáveis 
podem abranger o conteúdo de forma específica ou geral. Essa fase, para Artigue (1988) apud Machado (2016, p. 242) "deve ser concebida como uma análise do controle do sentido, pois a teoria das situações didáticas que serve de referência à metodologia da engenharia didática teve desde sua origem a ambição de constituir como uma teoria de controle das relações entre sentido e situações".

Esta análise tem por objetivo a identificação dos conhecimentos reais dos estudantes e posteriormente auxiliar no planejamento de fase/sessão para desenvolver os conhecimentos dos mesmos. Dessa maneira, é possível verificar o domínio, desempenho e esclarecer seu sentido. Assim, deve ser levado em consideração os seguintes tópicos descritos por Machado (2016):

- Descrever cada escolha referente às variáveis e as características das situações adidáticas decorrentes a cada escolha;

- Analisar o quanto é importante a proposta apresentada para o estudante verificar as possibilidades de ação, estabelecer estratégias, decisões a serem tomadas, controle e a validação que ocorrerá durante o processo;

- Prever os procedimentos possíveis que podem ser realizados e evidenciar que a análise realizada pode controlar o sentido desses comportamentos, garantindo assim a ampliação do conhecimento apontado pela aprendizagem.

Na terceira fase tem-se a experimentação, momento do qual apropria-se das análises já realizadas elabora-se atividades a partir dos resultados obtidos anteriormente. Esse é o momento em que a elaboração da atividade deverá ser construída de acordo com os levantamentos e pesquisas realizadas nas etapas anteriores. Assim, as pesquisas já realizadas devem ser colocadas em prática, dinamizando e norteando o desenvolvimento das atividades.

A quarta fase proposta pela Engenharia Didática constitui a análise a posteriori e validação. Nessa etapa, a análise a posteriori tem por objetivo se sustentar a partir dos dados coletados das amostras, durante a experimentação, para que assim possa se efetivar.

Já no que tange à validação, essa se dá pela comparação entre os resultados obtidos da amostra das fases, análise a priori e análise a posteriori, verificando a hipótese que o uso do software seria de grande contribuição para o ensino da Geometria e a consequente evolução do conhecimento da amostra. 


\section{Resultados obtidos}

$\mathrm{Na}$ análise preliminar ( $1^{\mathrm{a}}$ fase), os estudos foram baseados nas prescrições da versão preliminar da Base Nacional Comum Curricular (BNCC). Foram verificadas as habilidades que os estudantes deveriam possuir ao longo do Ensino Fundamental e do Ensino Médio, conforme ilustrado no Quadro 1.

Quadro 1: Conteúdos e habilidades da Geometria para o Ensino Fundamental

\begin{tabular}{|c|c|c|}
\hline Ano & Objetos de conhecimento & Habilidades \\
\hline $\begin{array}{l}1^{\circ} \\
\text { Ano }\end{array}$ & $\begin{array}{l}\text { Figuras geométricas planas: } \\
\text { reconhecimento do formato das faces } \\
\text { de figuras geométricas espaciais. }\end{array}$ & $\begin{array}{l}\text { (EF01MA14) Identificar e nomear figuras planas (círculo, } \\
\text { quadrado, retângulo e triângulo) em desenhos } \\
\text { apresentados em diferentes disposições ou em } \\
\text { contornos de faces de sólidos geométricos (p. 235). }\end{array}$ \\
\hline $\begin{array}{l}2^{\circ} \\
\text { Ano }\end{array}$ & $\begin{array}{l}\text { Figuras geométricas planas (círculo, } \\
\text { quadrado, retângulo e triângulo): } \\
\text { reconhecimento e características. }\end{array}$ & $\begin{array}{l}\text { (EF02MA15) Reconhecer, comparar e nomear figuras } \\
\text { planas (círculo, quadrado, retângulo e triângulo), por } \\
\text { meio de características comuns, em desenhos } \\
\text { apresentados em diferentes disposições ou em sólidos } \\
\text { geométricos (p. 239). }\end{array}$ \\
\hline $\begin{array}{l}3^{\circ} \\
\text { Ano }\end{array}$ & $\begin{array}{l}\text { Geometria Figuras geométricas } \\
\text { planas (triângulo, quadrado, } \\
\text { retângulo, trapézio e paralelogramo): } \\
\text { reconhecimento e análise de } \\
\text { características. }\end{array}$ & $\begin{array}{l}\text { (EF03MA15) Classificar e comparar figuras planas } \\
\text { (triângulo, quadrado, retângulo, trapézio e } \\
\text { paralelogramo) em relação a seus lados (quantidade, } \\
\text { posições relativas e comprimento) e vértices (p. } 245) \text {. }\end{array}$ \\
\hline $\begin{array}{l}4^{\circ} \\
\text { Ano }\end{array}$ & $\begin{array}{l}\text { Figuras geométricas planas: } \\
\text { características, representações e } \\
\text { ângulos. }\end{array}$ & $\begin{array}{l}\text { (EF05MA17) Reconhecer, nomear e comparar } \\
\text { polígonos, considerando lados, vértices e ângulos, e } \\
\text { desenhá-los, utilizando material de desenho ou } \\
\text { tecnologias digitais (p. 253). }\end{array}$ \\
\hline $\begin{array}{l}5^{\circ} \\
\text { Ano }\end{array}$ & $\begin{array}{l}\text { Polígonos: classificações quanto ao } \\
\text { número de vértices, às medidas de } \\
\text { lados e ângulos e ao paralelismo e } \\
\text { perpendicularismo dos lados. }\end{array}$ & $\begin{array}{l}\text { (EF06MA17) Reconhecer, nomear e comparar } \\
\text { polígonos, considerando lados, vértices e ângulos, e } \\
\text { classificá-los em regulares e não regulares, tanto em } \\
\text { suas representações no plano como em faces de } \\
\text { poliedros (p. 259). } \\
\text { (EF06MA18) Identificar características dos triângulos e } \\
\text { classificá-los em relação às medidas dos lados e dos } \\
\text { ângulos (p. 259). } \\
\text { (EF06MA19) Identificar características dos } \\
\text { quadriláteros, classificá-los em relação a lados e a } \\
\text { ângulos e reconhecer a inclusão e a intersecção de } \\
\text { classes entre eles (p. 259). }\end{array}$ \\
\hline
\end{tabular}




\begin{tabular}{|c|l|l|l|}
\hline $8^{\circ}$ & $\begin{array}{l}\text { Congruência de triângulos e } \\
\text { demonstrações de propriedades de } \\
\text { quadriláteros }\end{array}$ & $\begin{array}{l}\text { (EF08MA12) Demonstrar propriedades de quadriláteros } \\
\text { por meio da identificação da congruência de triângulos } \\
\text { (p. 265). }\end{array}$ \\
\hline
\end{tabular}

Fonte: Base Nacional Comum Curricular (BRASIL, 2016, versão preliminar)

No Quadro 2 é evidenciada a habilidade de Geometria pretendida para o Ensino Médio. Foram selecionados conteúdos específicos de Geometria que convergiam com a investigação dos quais seriam propostos aos estudantes.

Quadro 2: Habilidade da Geometria para o Ensino Médio

\begin{tabular}{|c|l|}
\hline Ano & Habilidade \\
\hline $3^{\circ}$ Ano & $\begin{array}{l}\text { MTMT3MOA233. Organizar logicamente os conhecimentos da Geometria plana, } \\
\text { construídos ao longo da Educação Básica, compreendendo o método axiomático. (p. 146) }\end{array}$ \\
\hline
\end{tabular}

Fonte: Base Nacional Comum Curricular (BRASIL, 2016, versão preliminar)

Com essas prescrições, os estudantes conseguiriam alcançar o nível 3 do modelo teórico de Van Hiele. No entanto, na análise deve-se dar ênfase também aos problemas relacionados aos conteúdos propostos pelo ensino, mas na prática nem sempre as ementas dos cursos superiores são cumpridas. É importante levar em consideração a escola em que estudaram e como estudaram, e se tiveram a disciplina de Geometria durante sua formação. Os problemas que são relacionados à sala de aula desencadeiam diferentes motivos para que o estudante não alcance os objetivos de aprendizagem prescritos. Desse modo, na análise a priori, poderia não alcançar o resultado esperado.

Na análise a priori, começou-se a definir as variáveis: a variável macrodidática foi realizar um estudo de figuras Geométricas Planas; variável microdidática são os acordos geridos entre 0 dinamizador e o estudante na aplicação regida junto ao contrato didático.

A aplicação ocorreu em uma sessão, no laboratório de informática do Instituto do Noroeste Fluminense de Educação Superior (INFES) da Universidade Federal Fluminense (UFF). Ao início da aplicação foi evidenciado o motivo da pesquisa e a importância da proposta, sendo para um trabalho de conclusão de curso e explicado como iria proceder. O jogo foi uma forma descontraída de aplicar uma avaliação diagnóstica, para identificar o nível de pensamento geométrico por meio do modelo de Van Hiele. 


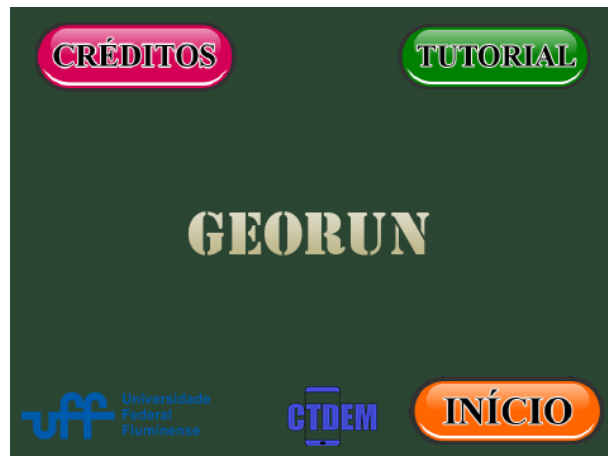

Figura 1: Tela inicial do jogo GeoRun (Elaboração dos Autores)

A tela inicial do jogo (Figura 1) é composta pelos créditos, por quem e porque foi criada, e pelo tutorial, como passos de como jogar e início para prosseguir com o jogo.

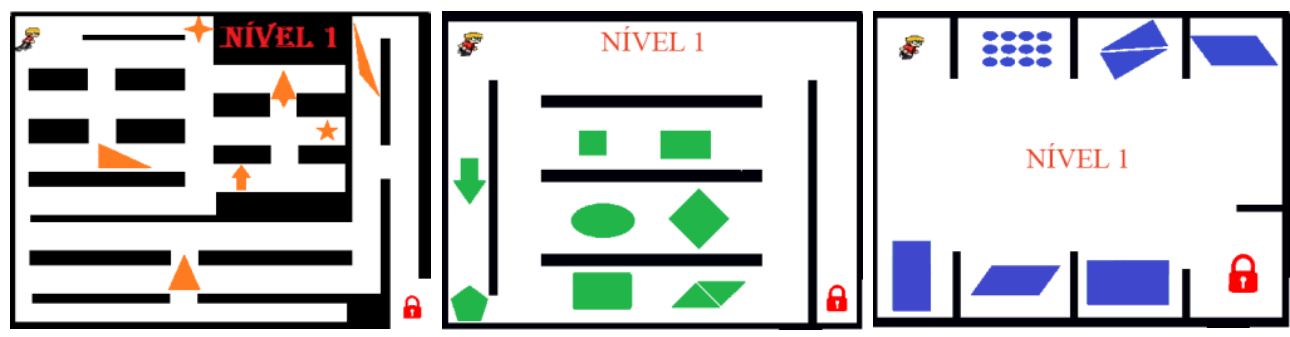

Figura 2: Jogo GeoRun, nível 1, etapas 1, 2 e 3 (Elaboração dos Autores)

O nível 1 (Figura 2), foi composto apenas de visualização, ao inicio de cada etapa, a uma tela explicando sobre qual figura geométrica coletar. Sendo assim, o estudante deveria pegar todas as figuras geométricas corretas.
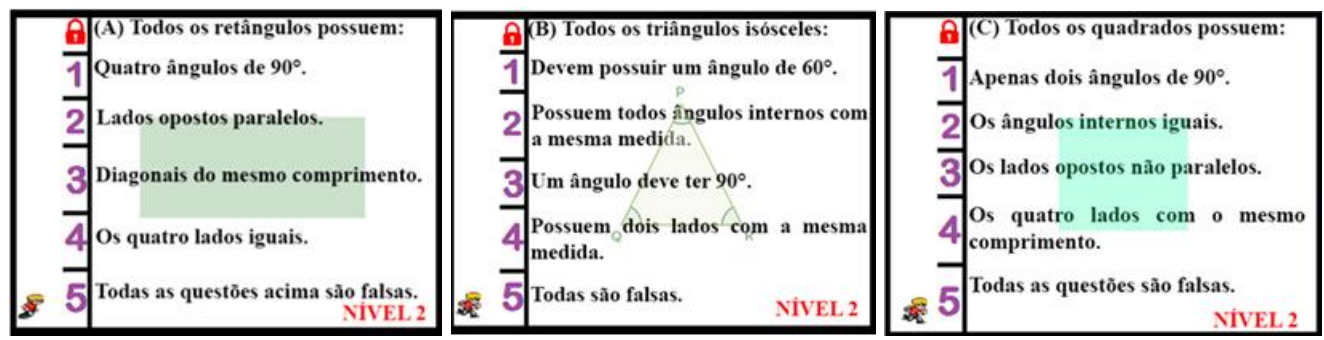

Figura 3: Jogo GeoRun, nível 2, etapas 1, 2 e 3 (Elaboração dos Autores)

O Nível 2 (Figura 3) foi estruturado por propriedades das figuras geométricas. Nessa fase, o estudante deveria coletar todos os números correspontes as propriedades corretas. 


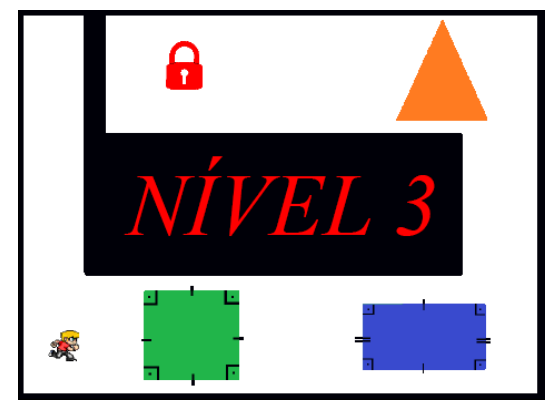

Figura 4: Jogo GeoRun, nível 3 (Elaboração dos Autores)

Já o nível 3 (Figura 4), é realizado de forma discursiva e ao encostar na figura geométrica, abre-se uma caixa de diálogo para o estudante responder. Neste nível, o aluno deve relacionar aquela figura geométrica com outra, de acordo com suas propriedades.

No jogo foram adaptados os níveis 1, 2 e 3 que eram propostos no modelo de Van Hiele sem perda de generalização. 0 nível 1 foi apenas de visualização; no nível 2 os estudantes deveriam identificar as propriedades das figuras geométricas de forma objetiva; e no nível 3 deveriam relacionar as figuras geométricas a outras figuras partindo de suas propriedades (das figuras geométricas).

Nos níveis 1 e 2, havia tanto questões certas como erradas. Foi uma maneira de analisar posteriormente o porquê da sua escolha errada, caso houvesse. Assim, tornou-se possível estabelecer estratégias a partir dos erros com o intuito de preparar uma aula para a experimentação com métodos adequados para a intervenção pedagógica. Após a aplicação da avaliação diagnóstica, cuja estruturação baseou-se na consideração dos conteúdos prescritos, obteve-se o seguinte resultado, conforme exposto no Quadro 3.

Quadro 3: Resultado do conhecimento geométrico dos estudantes

\begin{tabular}{|c|c|}
\hline Nível & Estudantes \\
\hline Sem nível (Não atingiu nenhum) & 8 \\
\hline Nível 1 (Visualização) & 0 \\
\hline Nível 2 (Análise) & 5 \\
\hline Nível 3 (Dedução informal) & 2 \\
\hline
\end{tabular}

Fonte: Dados da Pesquisa

Assim, foram levantados bons resultados para que sejam confrontados entre a análise a priori e a análise a posteriori para a possível validação. A amostra foi de quinze estudantes que 
estavam inscritos na disciplina de Fundamentos da Geometria do curso de Licenciatura em Matemática. Assim, para realizar a próxima etapa (experimentação) foram levados em consideração os conhecimentos identificados na análise a priori. Adotamos como hipótese que 0 uso do software seria de grande contribuição para o ensino da Geometria, podendo potencializar o desenvolvimento da visualização geométrica e contribuir para a construção dos conhecimentos.

Na experimentação, é o momento de tudo que já foi realizado ser colocado em prática, no qual se utiliza da análise realizada na fase anterior e elaboram-se atividades a partir dos dados coletados da amostra.

Para a realização desta atividade adaptou-se uma estrutura para que os estudantes compreendessem novos conceitos, os quais não foram apreendidos ou precisariam ser relembrados. Os estudos realizados junto a eles foram feitos por meio da área computacional, usando o software GeoGebra, para que conseguissem fazer diversas alterações em pouco tempo e conseguir assimilar os conceitos e padrões de acordo com essas modificações.

O GeoGebra possibilita a ilustração daquilo que muitas vezes fica só na teoria e não é compreendido de forma visual e prática, podendo ser possível entender os conceitos matemáticos. O software permite potencializar a aula, tornando-a dinâmica e possibilitando maior acompanhamento dos estudantes. 0 GeoGebra está disponível para download gratuitamente nas plataformas Linux, Windows, Chrome OS, Mac, Android e IOS. A aplicação foi realizada no laboratório de informática do INFES/UFF, onde as máquinas do local tinham o sistema operacional Linux, não trazendo entraves, visto que o funcionamento do GeoGebra é padrão para todos os sistemas operacionais.

A elaboração da intervenção pedagógica foi desenvolvida para suprir pelo menos a maior dificuldade encontrada na turma, de identificar cada figura geométrica, uma vez que possivelmente a partir das análises realizadas na visualização, os estudantes poderiam definir suas propriedades e também suas inclusões de classes. Para que isso fosse possível e para que não houvesse entraves no uso do GeoGebra, as figuras foram desenvolvidas anteriormente e levadas em arquivos para que pudessem fazer interações com as mesmas e sempre continuarem tendo as mesmas propriedades, conforme Figura 5. 

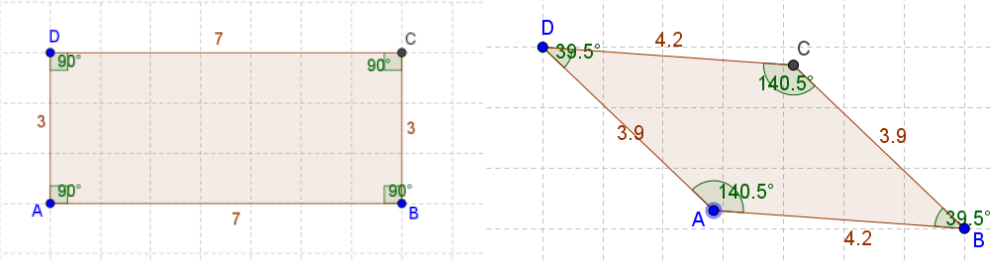

Figura 5: Paralelogramo no GeoGebra (Dados da Pesquisa)

As construções têm a função proposta pelo software, a figura está pré-definida para que o estudante possa fazer infinitas modificações com ela e, nesse caso, não deixar de ser paralelogramo; a alteração feita foi 0 arraste do vértice $A$. Independente do vértice que for alterado ou da forma que for mexido nunca vai deixar de ser um paralelogramo.

Do mesmo modo desenvolvido para o paralelogramo, também foi realizado para as outras figuras geométricas estudadas, como o quadrado, losango, retângulo e triângulo. Dessa forma, torna-se mais simples a identificação e reconhecimento das propriedades, pois os estudantes que se encontram nessa amostra já passaram por esses tipos de conhecimentos e precisavam apenas recordar.

Essa sessão foi realizada para a mesma amostragem da qual foi realizada a análise a priori. A duração dessa intervenção pedagógica foi de uma hora, realizada durante um tempo de aula da disciplina Fundamentos da Geometria.

Foram distribuídas duas folhas contendo os nomes das figuras geométricas e espaços para que pudessem preencher ao decorrer da aula. O software já estava instalado nas máquinas e prontos para iniciarem.

Foi explicado que os estudos eram referentes apenas às figuras geométricas que se encontravam na folha entregue e que as respostas deveriam ser estudadas junto ao software GeoGebra, para que pudessem compreender os padrões das figuras e assim responder suas propriedades.

Para que pudessem sempre estar juntos na atividade, foi estabelecido um contrato didático para a análise de cada figura geométrica. Os estudantes possuíam 10 minutos para cada figura, realizando a descrição de suas propriedades ou caso todos da turma terminassem de definir tais propriedades da presente figura, era possível seguir para a próxima.

A aplicação aconteceu de forma individual, cada estudante utilizou seu computador e folha de resposta. Durante essa sessão, além da folha de resposta, foram observadas as dúvidas 
e dificuldades, alguns erros cometidos durante o procedimento, para que pudessem ser analisados junto à análise a posteriori.

O tempo estimado para que concluíssem a atividade de cada figura geométrica não foi excedido em nenhum caso. Ao finalizarem as discussões das propriedades de todas as figuras geométricas, voltamos novamente à questão da inclusão de classes, conforme foram descritas as propriedades geométricas, a partir delas quais são relacionadas com as outras.

Desse modo, foi possível estudar novamente os três níveis. Os estudantes que não atingiram nem a visualização, ao se depararem com 0 arquivo estavam lidando com o nível 1 (visualização), compreendendo a figura, e ao descreverem as propriedades estavam entrando no nível 2 (análise), e, por fim, se a partir delas conseguissem fazer as relações necessárias entres as figuras se classificavam como nível 3 (dedução informal).

Portanto, ao encerramos a sessão, foram entregues as atividades resolvidas; também consideramos as perguntas e conversas, dúvidas e dificuldades do momento de experimentação. Todos os dados colhidos serviram de instrumentos para serem discutidos na análise a posteriori.

A análise a posteriori e validação têm por objetivo realizar a justaposição de todos os dados coletados das amostras, durante a experimentação. Portanto, a validação se dá pela comparação entre as análises a priori e a posteriori feitas, podendo assim validar as hipóteses de pesquisa levantadas.

Por meio da intervenção pedagógica, das atividades aplicadas, questionário respondido, conversas, dúvidas, observações de dificuldade e erros, procedemos à análise a posteriori que visa conferir estes dados, para a validação da Engenharia Didática.

Assim, foi realizada análise das respostas da atividade aplicada na experimentação para confrontá-la com a análise a priori. Para verificação das respostas das propriedades e os conceitos, foi adotado o livro de Fundamentos de Matemática Elementar, volume 9, Geometria Plana, $9^{a}$ edição, publicado em 2013, de autoria de Osvaldo Dolce e José Nicolau Pompeo.

\section{Sobre os triângulos}

Tem-se por definição de um triângulo, a união de três pontos não colineares, formando assim três segmentos. Tomando os pontos como $\mathrm{A}, \mathrm{B}, \mathrm{C}$, tem-se os seguintes segmentos $\overline{A B}$, $\overline{A C}, \overline{B C}$, formando, assim, o triângulo $\mathrm{ABC}$. Por indicação temos: 
Triângulo $A B C=\triangle A B C$, conforme Figura 6

$\triangle \mathrm{ABC}=\overline{A B} \cup \overline{A C} \cup \overline{B C}$

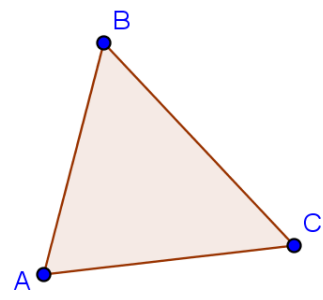

Figura 6: Triângulo $A B C=\triangle A B C$ (Elaboração dos Autores)

Há várias classificações de triângulo, como equiláteros, isósceles, escalenos, acutângulos, retângulo e obtusângulo, conforme podemos observar no Quadro 4.

Quadro 4: Classificação e definições de triângulos

\begin{tabular}{|c|c|c|}
\hline Classificação & Definição \\
\hline Equilátero & $\begin{array}{c}\text { Se, e somente se, tem os três lados } \\
\text { congruentes, ou seja, possuem os três } \\
\text { lados com medidas iguais. }\end{array}$ \\
\hline Isósceles & $\begin{array}{c}\text { Se, e somente se, tem dois lados } \\
\text { congruentes, ou seja, possuem dois lados } \\
\text { com medidas iguais. }\end{array}$ \\
\hline Escaleno & $\begin{array}{c}\text { Se, e somente se, tem dois quaisquer } \\
\text { lados não congruentes, ou seja, possui os } \\
\text { três lados com medidas diferentes. }\end{array}$ \\
\hline Acutângulo & $\begin{array}{c}\text { Se, e somente se, tem os três ângulos } \\
\text { internos agudos, ou seja, possuem todos } \\
\text { os ângulos com medidas menores que } \\
90^{\circ} \text {. }\end{array}$ \\
\hline
\end{tabular}




\begin{tabular}{|c|c|c|}
\hline Retângulo & $\begin{array}{c}\text { Se, e somente se, tem um ângulo interno } \\
\text { reto, ou seja, possui um ângulo com } \\
\text { medida igual a } 90^{\circ} .\end{array}$ \\
\hline Obtusângulo & $\begin{array}{c}\text { Se, e somente se, tem um ângulo interno } \\
\text { obtuso, ou seja, um ângulo maior que } \\
90^{\circ} .\end{array}$ \\
\hline
\end{tabular}

Fonte: Dolce e Pompeo (2013, p. 38)

Os triângulos possuem $180^{\circ}$ como soma de seus ângulos internos, em qualquer uma das classificações. Quando o triângulo for retângulo, tem-se que o lado oposto ao ângulo reto é a sua hipotenusa, e os outros dois lados são os catetos do triângulo.

\section{Sobre os quadriláteros}

$\mathrm{Na}$ abordagem obtida na análise a priori teve apenas o retângulo e o quadrado, mas tem-se como quadriláteros notáveis também o paralelogramo e o losango, o que pode causar algumas dúvidas durante o processo.

Os quadriláteros tratados são convexos, ou seja, a reta que une dois vértices consecutivos não encontra o lado formado pelos dois outros vértices. Dessa forma, têm-se as definições, organizadas no Quadro 5.

Quadro 5: Definição dos quadriláteros notáveis

\begin{tabular}{|c|c|c|}
\hline Quadrilátero & Definição & $\begin{array}{c}\text { É um polígono de quatro lados, } \\
\text { cujo lados opostos são paralelos, } \\
\text { popostos e lados opostos } \\
\text { congruentes. }\end{array}$ \\
\hline Paralelogramo & $\begin{array}{c}\text { É um polígono de quatro lados, } \\
\text { eujo lados opostos são paralelos } \\
\text { e possui os quatro ângulos } \\
\text { congruentes, ou seja, de 90\% }\end{array}$ \\
\hline Retângulo
\end{tabular}




\begin{tabular}{|c|c|c|c|}
\hline Losango & $\begin{array}{c}\text { É um polígono de quatro lados, } \\
\text { cujo lados são congruentes. }\end{array}$ & $\begin{array}{c}\text { É um polígono de quatro lados, } \\
\text { cujo lados e ângulos são } \\
\text { congruentes. }\end{array}$ \\
\hline Quadrado & & \\
\hline
\end{tabular}

Fonte: Dolce e Pompeo (2013, p. 100-101)

A partir das definições, tem-se as propriedades dos quadriláteros.

Paralelogramo:

$\checkmark$ Ângulos opostos congruentes:

- Qualquer paralelogramo possui dois ângulos opostos congruentes;

- Todo quadrilátero que tem ângulos opostos congruentes é paralelogramo;

- Todo retângulo é paralelogramo.

Lados opostos congruentes:

- Qualquer paralelogramo possui lados opostos congruentes;

- Todo quadrilátero de lados opostos congruentes é um paralelogramo;

- Todo losango é um paralelogramo.

Diagonais:

- Em todo paralelogramo, as diagonais interceptam o mesmo ponto médio;

- Sempre que se tem um quadrilátero em que as diagonais interceptam o mesmo ponto médio, tem-se um paralelogramo;

- Portanto, se dois segmentos de reta se interceptam nos respectivos pontos médios, então tem-se que as extremidades são vértices de um paralelogramo.

Dois lados paralelos e congruentes: 
- Todo quadrilátero que possui dois lados paralelos e congruentes é um paralelogramo;

- Se dois segmentos de retas são paralelos e congruentes então suas extremidades são vértices de um paralelogramo.

Após as propriedades dos paralelogramos, resta evidenciar as propriedades do retângulo, losango e quadrado. Essas propriedades foram organizadas em sequência, pois possuem um elo em comum.

Sobre o retângulo:

- Possui as propriedades do paralelogramo;

- O retângulo tem suas diagonais congruentes;

- Todo paralelogramo que possui suas diagonais congruentes é um retângulo.

Sobre o losango:

- Possui as propriedades do paralelogramo;

- Sua característica é que as diagonais são perpendiculares entre elas;

- Todo paralelogramo que possui as diagonais perpendiculares entre elas é um losango.

Sobre o quadrado:

- Possui as propriedades do paralelogramo;

- Sua característica é que as diagonais são congruentes e perpendiculares entre elas;

- Todo quadrado, pelas definições, é retângulo e também losango.

Portanto essas propriedades abordadas são dos quadriláteros convexos, como já mencionados anteriormente. Resumindo, se levarmos em consideração as diagonais, elas se cortam ao meio; o paralelogramo é quando as diagonais se cruzam; o retângulo quando as diagonais forem congruentes; o losango quando as diagonais são perpendiculares entre si; e o quadrado possui diagonais congruentes e perpendiculares. 
Dessa maneira, a experimentação teve sua atividade elaborada com 0 intuito de estimular os estudantes com as alterações da própria figura de modo visual e forma que continuassem com a mesma propriedade.

Analisando as respostas dos questionários da amostragem, foi perceptível o crescimento do conhecimento geométrico. Como já descrito anteriormente, as respostas dadas verificam novamente o conhecimento geométrico de acordo com o modelo de Van Hiele. A análise foi realizada de forma manual.

Primeiramente, para que a visualização ficasse clara e não houvesse entraves com a utilização do GeoGebra, as figuras geométricas já haviam sido criadas e de forma que não poderiam deixar suas propriedades, deixando de modo claro as diversas formas que aquele tipo de figura poderia adotar para receber seu devido nome, sendo ela paralelogramo, quadrado, losango, retângulo ou triângulo. Assim, todos obtiveram visualmente o conhecimento de como é cada figura geométrica.

Desse modo, os estudantes que estavam presentes passaram a conhecer as figuras geométricas pelas suas devidas formas tornando, assim, primeiramente seu nível de compreensão geométrico como nível 1 (visualização).

Em segundo, o GeoGebra é uma ferramenta que pode ser feitas interações instantâneas e infinitamente rápidas, diferentes de quando desenhamos. A visualização é um fator muito importante na Geometria; sempre que as alterações eram realizadas as figuras se mantinham com as mesmas propriedades. Essa função foi criada para que independente da alteração que fosse realizada, suas propriedades continuassem as mesmas tornando assim a análise mais compreensiva.

Com a visualização, as figuras geométricas tiveram diversas respostas sobre propriedades, escritas de formas pessoais, mas que atendiam as propriedades descritas pelo livro. Abaixo algumas das respostas obtidas por diferentes estudantes, conforme figuras 7,8 e 9 .

$$
\begin{aligned}
& \text { 2. Quadrado } \\
& \text { Todos es ánqulos sad retos, todos os lados tem } \\
& \text { a mesma medida, diagonais rad vionais }
\end{aligned}
$$

Figura7: Propriedades citadas pelo estudante sobre o quadrado (Dados da Pesquisa) 


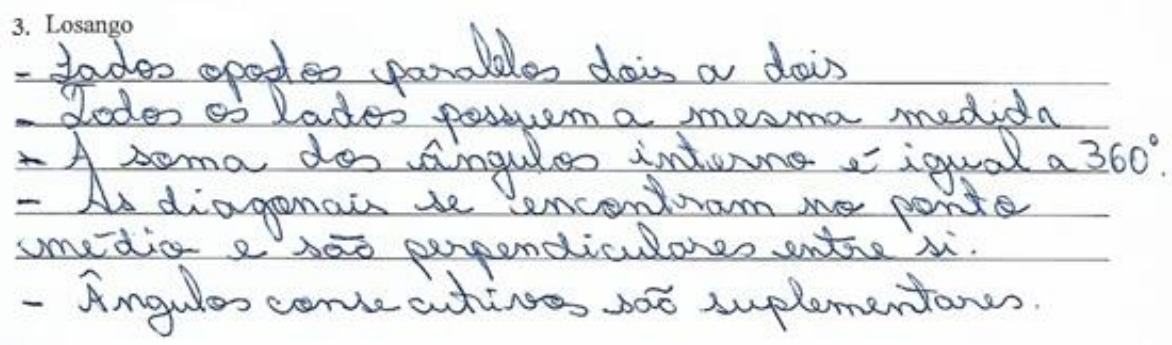

Figura 8: Propriedades citadas pelo estudante sobre o losango (Dados da Pesquisa)

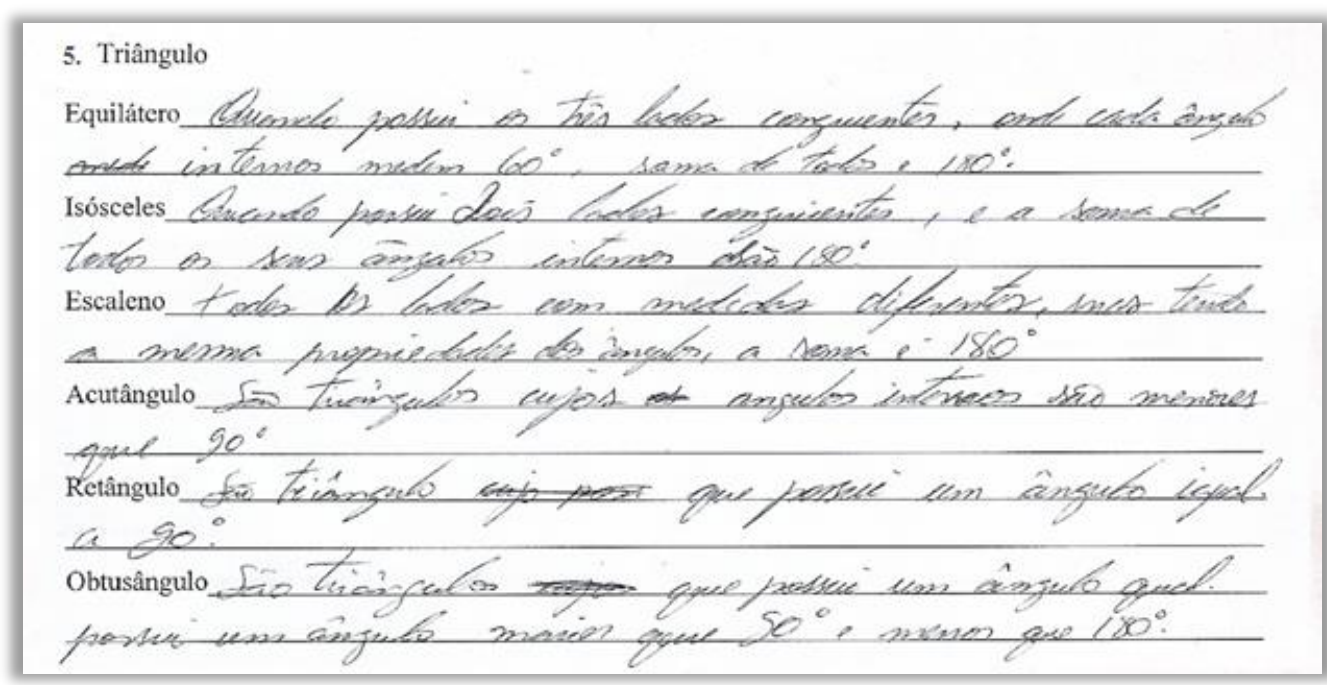

Figura 9: Propriedades citadas pelo estudante sobre o triangulo (Dados da Pesquisa)

Como a amostragem era de quinze estudantes, foram escolhidas apenas três respostas aleatórias e figuras geométricas diferentes. Essas são algumas produzidas por estudantes que foram evidenciadas no GeoGebra durante a intervenção pedagógica. As mesmas estão de acordo com os conceitos abordados nos livros, o que leva a evidenciar que todos que tiveram a mesma percepção e a geração dessas respostas adequadas, estão de acordo com 0 nível de conhecimento geométrico 2 (análise).

Entretanto, apenas três estudantes da amostra não conseguiram descrever corretamente as propriedades geométricas das figuras, sendo classificados no nível de visualização do modelo.

Já a última questão do formulário dado para ser preenchido se tratava do nível 3 (dedução informal) do modelo teórico de Van Hiele. Foi solicitado para que os estudantes, de acordo com o que já haviam compreendido sobre as outras figuras geométricas, estabelecessem os nomes das figuras que possuíam relação entre si, conforme as Figuras 10, 11 e 12. 
6. De acordo com as propriedades descritas acima, há figuras geométricas nas quais recebem as mesmas propriedades, como consequência pode ser chamada de ambos os nomes? Caso afirmativo, cite as que conseguiu reconhecer.

Joudvo q quatnotio í um lassango

Souds retênguls, quadrado e seasango í um quadriláterro

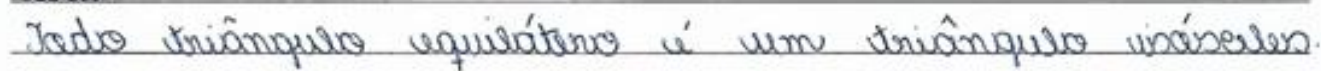

Figura 10: Inclusão de classe citada pelo estudante 3 (Dados da Pesquisa)

6. De acordo com as propriedades descritas acima, há figuras geométricas nas quais recebem as mesmas propriedades, como consequência pode ser chamada de ambos os nomes? Caso afirmativo, cite as que conseguiu reconhecer.

Q quadrado atende an mesmas proprieclades de rotongula i de losango, as trés

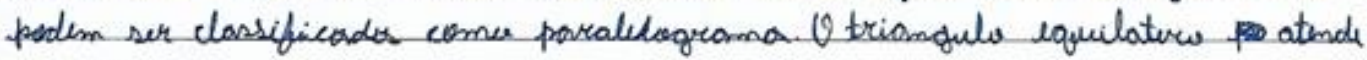
a prepriestade de isorales I de acutangulo

Figura 11: Inclusão de classe citada pelo estudante 5 (Dados da Pesquisa)

6. De acordo com as propriedades descritas acima, há figuras geométricas nas quais recebem as mesmas propriedades, como consequência pode ser chamada de ambos os nomes? Caso afirmativo, cite as que conseguiu reconhecer.

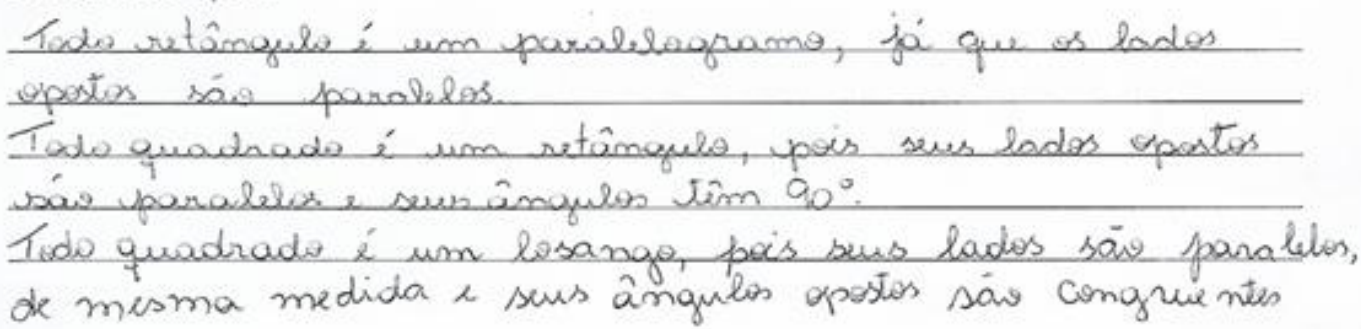

Figura 12: Inclusão de classe citadas pelo estudante 10 (Dados da Pesquisa)

As respostas dadas foram escolhidas aleatoriamente, entre os estudantes que haviam conseguido atingir o nível. Na experimentação, com a abordagem do GeoGebra, a maior parte dos estudantes conseguiu assimilar a relação entre as figuras e concluir pelo menos uma inclusão. Apenas seis estudantes não conseguiram completar este nivel.

Foi possivel constatar, no decorrer da intervenção, que o GeoGebra proporcionou grande auxílio no reconhecimento das propriedades das figuras geométricas. A dinamicidade que o software proporciona durante o estudo realizado foi de grande contribuição. Dessa maneira, 
foram amenizadas as dúvidas que poderiam ter surgido, pois foi possível fazer alterações até se sentirem confortáveis a responderem as propriedades correspondentes.

$\mathrm{Na}$ intervenção pedagógica foi organizado o contrato didático de forma que 0 andamento da aula ocorresse de forma coletiva. A próxima questão só era iniciada quando todos haviam finalizado ou o tempo havia esgotado, o que não aconteceu. Dessa forma, o andamento e construção de conhecimento aconteceu de forma coletiva. $O$ trabalho realizado com software para a grande parte foi extremamente útil para que pudesse aprender ou relembrar o conteúdo. Com a utilização dos recursos, foi notável a participação, até mesmo por todos os questionários terem sidos completamente preenchidos; a intervenção foi um momento expressivo de aprendizagem sobre a Geometria.

A contribuição do GeoGebra foi relevante para que expusessem os conceitos das figuras geométricas correspondentes; essa contribuição pode ser notada nas resoluções obtidas nas folhas de respostas, onde conseguiram progredir muito em comparação com a primeira sessão.

$\mathrm{Na}$ análise a priori e a posteriori, temos um estudo de caso proposto com os mesmos sujeitos de pesquisa. Constatou-se que a análise a priori foi de grande relevância, por apresentarem conhecimentos sobre a Geometria, divergentes do que constavam os currículos, conforme já havia sido previsto. Dessa maneira, foi possível identificar o nível individual para a elaboração de um conteúdo para contribuição dos conhecimentos dos estudantes. Assim, tem-se o Quadro 6 com o resultado entre as análises.

Quadro 6: Confronto de resultados entre a análise a priori e a análise a posteriori

\begin{tabular}{|l|l|}
\hline \multicolumn{2}{|c|}{ Análise a Priori } \\
\hline Sem nível & 8 \\
\hline Nível 1 (Visualização) & 0 \\
\hline Nível 2 (Análise) & 5 \\
\hline Nível 3 (Dedução informal) & 2 \\
\hline
\end{tabular}

\begin{tabular}{|l|l|}
\hline \multicolumn{2}{|c|}{ Experimentação } \\
\hline Sem nível & 0 \\
\hline Nível 1 (Visualização) & 3 \\
\hline Nível 2 (Análise) & 3 \\
\hline Nível 3 (Dedução informal) & 9 \\
\hline
\end{tabular}

Fonte: Dados da Pesquisa

O planejamento organizado na experimentação mostrou-se eficaz e o desenvolvimento dos conhecimentos entre os conceitos e as figuras geométricas foi de grande relevância. O nível de conhecimento geométrico dos estudantes foi bem mais satisfatório que na primeira etapa realizada (análise a priori), sendo que na análise a priori mais da metade da amostra não 
conseguiu atingir nenhum nível. Já na experimentação, mais da metade da amostragem evidenciou que foi possível à assimilação do conteúdo com auxílio do software.

A análise a priori foi de fundamental importância para que o nosso estudo fosse validado. Ela tornou possível constatar o crescimento satisfatório obtido com a experimentação de acordo com os estudos feitos na análise a posteriori, visto que a simulação das figuras é válida para 0 estudo da Geometria, e por fim esses resultados culminando na validação do processo da Engenharia Didática construída. Portanto, a hipótese que trata a construção do conhecimento geométrico dos estudantes com auxílio de software prevista na análise a priori é válida.

\section{Considerações}

Nesta pesquisa foi adotado o modelo teórico de Van Hiele e seus níveis de pensamento geométrico, tendo como objetivo identificar o conhecimento da amostra de acordo com o modelo e, a partir dessa etapa, planejar uma sessão de ensino (intervenção pedagógica) que culminasse em uma melhor compreensão.

A metodologia, ao analisar cuidadosamente suas etapas, trouxe enriquecimento para a abordagem e estruturação dos conteúdos da investigação. Com o auxílio da Engenharia Didática, foram analisadas a versão preliminar da BNCC (BRASIL, 2016), da qual foi realizada uma abordagem dos conteúdos sobre a Geometria.

Na primeira sessão, a amostra apresentou um resultado insatisfatório, por mais da metade da turma não ter conseguido alcançar ao menos o nível de visualização. Ao finalizar a sessão foi possível identificar o nível de cada participante. A contribuição da metodologia para essa pesquisa foi norteadora, gerando reflexões e contribuindo para o planejamento/ação do ensino por ser um instrumento que potencializa e traz reflexões sobre as intervenções pedagógicas e as possíveis situações de aprendizagem que a Engenharia gerou.

Com a utilização do GeoGebra foi possível verificar, por meio das respostas, o aumento do grau de compreensão da turma referente ao assunto tratado. A abordagem realizada foi de apenas uma sessão/aula e foi possível notar evolução nesse reestudo dos conceitos das figuras geométricas, o que confirmou a hipótese levantada na análise a priori.

Em vias de finalização, pode-se sinalizar ser relevante que os estudantes de Geometria sejam inseridos cada vez mais em situações didáticas que se utilizem de tais ferramentas para 
que torne possivel potencializar visualmente as atividades, uma vez que a Geometria está intrinsecamente ligada a visualização e compreensão dos conteúdos.

Salienta-se a necessidade cada vez mais eminente de investimentos em cursos de formação continuada dos professores, para que consigam suprir as demandas que o contexto escolar apresenta, inteirando um pouco da diversidade encontrada nas salas de aula, agregando conhecimento e transformando-o no contexto escolar.

\section{Referências}

ALVES, George de Souza; SAMPAIO, Fábio Ferrentini. O modelo de desenvolvimento do pensamento geométrico de Van Hiele e possíveis contribuições da geometria dinâmica. Revista de Sistemas de Informação da FSMA, Macaé, n. 5, p. 69-79, 2010.

ALVES, George. Um estudo sobre o desenvolvimento da visualização geométrica com o uso do computador. In: SIMPÓSIO BRASILEIRO DE INFORMÁTICA NA EDUCAÇÃO, 2007, XVIII, São Paulo. Anais do XVIII SBIE. São Paulo: Universidade Mackenzie, 2007, p.1-10.

BARROS, Felipe de Carvalho. O jogo computacional YOGEO como ferramenta de análise dos niveis de Van Hiele. 2009. Trabalho de Conclusão de Curso (Licenciatura em Matemática). Universidade Federal Rural do Rio de Janeiro. Rio de Janeiro.

BRASIL. Ministério da Educação. Secretaria de Educação Básica. Base Nacional Comum Curricular (versão preliminar). Brasília: MEC/SEB, 2016.

BRASIL. Ministério da Educação. Secretaria da Educação Média e Tecnológica. PCN+ Ensino Médio - Orientações Educacionais Complementares aos Parâmetros Curriculares Nacionais: Ciências da Natureza, Matemática e suas Tecnologias. Brasília: MEC/SEMT, 2002.

DOLCE, Osvaldo; POMPEO, José Nico. Fundamentos de Matemática Elementar: Geometria Plana. v. 9. São Paulo: Atual, 2013.

KALEFF, Ana Maria; HENRIQUES, Almir de Souza; REI, Duke Monteiro; FIGUEIREDO, Luiz Guilherme. O desenvolvimento do pensamento geométrico: o Modelo de Van Hiele. Bolema, Rio Claro, v. 9, n. 10, p. 1-8, 1994

MACHADO, Silvia Dias Alcântara. Engenharia Didática. In: MACHADO, Silvia Dias Alcântara. (Org.) Educação Matemática: uma (nova) introdução. São Paulo. EDUC, 2016, p. 233-247.

MIRANDA, Guilhermina Lobato. Limites e possibilidades das TIC na educação. Revista de Ciências da Educação, Lisboa, n. 3, p. 41-50, 2007.

MORELATTI, Maria Raquel Miotto; SOUZA, Luís Herique Gazeta de. Aprendizagem de conceitos geométricos pelo futuro professor das séries iniciais do ensino fundamental e as novas tecnologias. Educar em Revista, Curitiba, n. 28, p. 263-275, jul./dez. 2006. 
NASSER, Lilian. O desenvolvimento do raciocínio em Geometria. São Paulo: Editora Brasil, 2015.

SILVA, Benedito Antonio. Contrato Didático. In: MACHADO, Silvia Dias Alcântara. (Org.) Educação Matemática: uma (nova) introdução. São Paulo. EDUC, 2016, p. 49-75. 